\title{
Water vapor transport for spring persistent rains over southeastern China based on five reanalysis datasets
}

\author{
Puxi Li ${ }^{1,2} \cdot$ Tianjun Zhou ${ }^{1,2} \cdot$ Xiaolong Chen ${ }^{1}$
}

Received: 11 December 2016 / Accepted: 5 April 2017 / Published online: 12 April 2017

(c) The Author(s) 2017. This article is an open access publication

\begin{abstract}
In this study, atmospheric water vapor transport was analyzed to study the changes in spring persistent rainfall (SPR) over southeastern China from 1980 to 2012. The performances of five sets of reanalysis data in reproducing the climatology, the long-term trend and interannual variability of the SPR were synthetically evaluated. To understand the mechanisms dominating SPR variation, the major components of moisture budget, including vertical moisture advection, horizontal moisture advection and evaporation, were examined based on the five reanalysis datasets. The results show that all five reanalysis datasets reproduce the climatology of the SPR reasonably well. Strong westerly wind flow over the southern Tibetan Plateau and southwest wind flow over the western North Pacific are the two main channels remotely supplying water vapor for the SPR. Locally, moisture budget diagnosis shows that the SPR is primarily contributed by the evaporation and vertical moisture advection terms. The SPR shows a decreasing tendency $\left[-0.38 \mathrm{~mm} \mathrm{day}^{-1}(10 \text { year })^{-1}\right]$ during 1980-2012 along with strong interannual variation, which is reasonably captured by all five reanalysis datasets. Vertical moisture advection dominates the SPR variation,
\end{abstract}

This paper is a contribution to the special issue on East Asian Climate under Global Warming: Understanding and Projection, consisting of papers from the East Asian Climate (EAC) community and the 13th EAC International Workshop in Beijing, China on 24-25 March 2016, and coordinated by Jianping Li, Huang-Hsiung Hsu, Wei-Chyung Wang, Kyung-Ja Ha, Tim Li, and Akio Kitoh.

Tianjun Zhou

zhoutj@lasg.iap.ac.cn

1 LASG, Institute of Atmospheric Physics, Chinese Academy of Science, Beijing 100029, China

2 University of Chinese Academy of Sciences, Beijing, China and the decreasing trend of the SPR is mainly due to the weakening of ascending motion during this period. In an El Niño decaying spring, the anomalous lower-tropospheric anticyclone over the western North Pacific intensifies vertical upward motion and leads to more precipitation. Both the Japanese 55-year reanalysis (JRA55) and the European Centre for Medium-Range Weather Forecast interim reanalysis (ERAIM) show higher skill in reproducing the climatology and changes of the SPR.

Keywords Water vapor transport $\cdot$ Spring persistent rains $\cdot$ Reanalysis data $\cdot$ Moisture budget diagnosis

\section{Introduction}

Spring persistent rainfall (SPR) is a unique synoptic and climatic phenomenon in East Asia, spanning the 13th to 27th pentads of the solar year (Tian and Yasunari 1998). The distribution and intensity of the SPR rain belt are subject to the topography of the "Nanling" $\left(24-26.5^{\circ} \mathrm{N}\right.$, $\left.110-116^{\circ} \mathrm{E}\right)$ and "Wuyi" $\left(25-29^{\circ} \mathrm{N}, 116-119^{\circ} \mathrm{E}\right)$ Mountains (Wan and Wu 2007, 2008; Zhang et al. 2013). Over southeastern China, boreal spring rainfall, featured by high frequency (Huang et al. 2015b), accounts for approximately $35 \%$ of the annual accumulation (shown in Fig. 1b). As a climatic phenomenon, the SPR is the major rainy period before the Meiyu/Baiu in early summer over the middle and lower reaches of the Yangtze River. Spring is the important period in the transition of atmospheric circulation from winter monsoon state to summer, significantly influencing the onset of the summer monsoon (Wang et al. 2002; Pan and Jiang 2014; Wu et al. 2015). Since southeastern China is one of the most important economic agricultural regions, 
Fig. 1 Climatology of spring persistent rains (SPR) over southeastern China based on GPCP data and Chinese rain gauge observation dataset: a spatial distributions of SPR based on GPCP data (unit: $\mathrm{mm} \mathrm{day}^{-1}$ ); $\mathbf{b}$ the same as $\mathbf{a}$, but derived from Chinese rain gauge observation dataset; $\mathbf{c}$ percentage of climatological SPR in the annual total based on GPCP (unit: \%); d the same as c, but for Chinese rain gauge observation dataset. The rectangle indicates the major rainfall center (a) Climatology(GPCP)

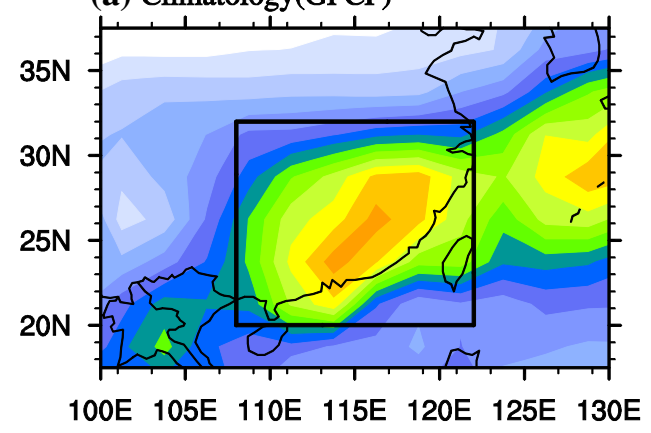

(b) Climatology(station)

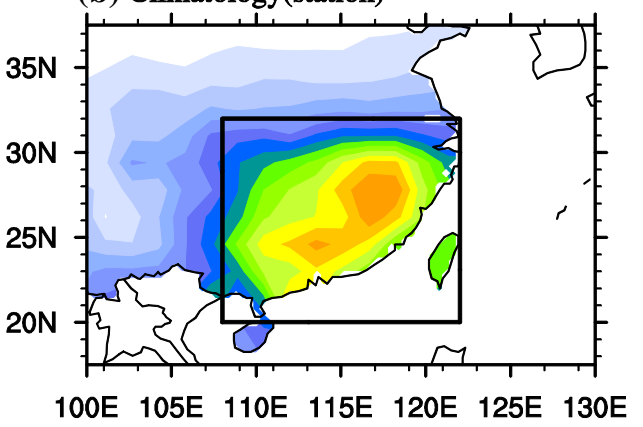

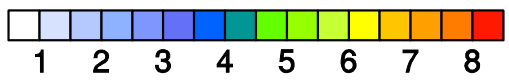

(c) Percentage(GPCP)

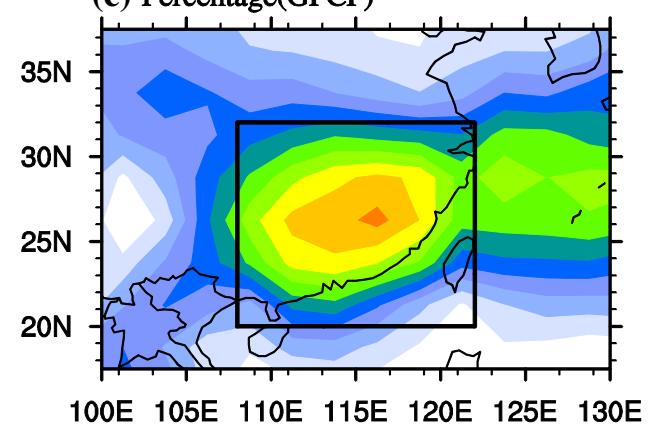

(d) Percentage(station)

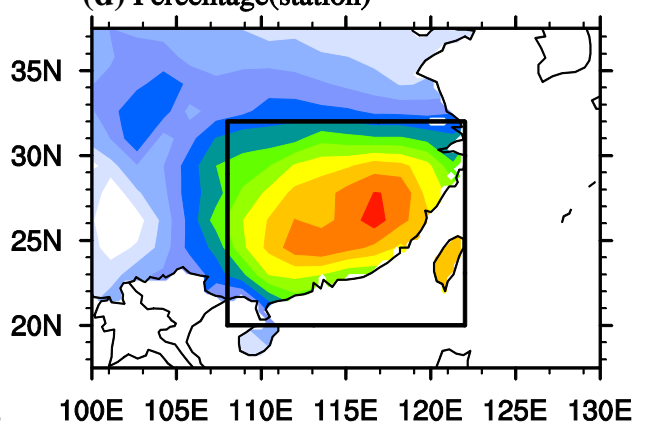

it is necessary to understand variations of the SPR and responsible mechanisms from the climate respective.

Much effort has been devoted to studying the SPR. Tian and Yasunari (1998) first proposed the concept of "SPR". They found that the east-west thermal contrast between the Indochinese Peninsula and the western North Pacific, which is due to the time-lag of seasonal warming in the spring, is the main mechanism of SPR formation. The mechanical and thermal forcing of the Tibetan Plateau (TP) also plays primary roles in the formation of the SPR (Wan and Wu 2007; Wan et al. 2009). For interannual variability, previous studies have suggested a strong linkage between the intensity and frequency of the SPR over southeastern China and the East Asian subtropical jet (i.e., EASJ; Wen et al. 2007; Deng et al. 2014). The oceanic thermal condition over the equatorial Pacific and the South China Sea can also influence the variability of the SPR (Yang and Lau 2004; Qiang and Yang 2013; Chen et al. 2014; Wu et al. 2015). Wan et al. (2008) suggested that there is a strong relationship between the Multivariate ENSO Index in the preceding winter and the SPR. In an El Niño decaying spring, an anticyclonic circulation anomaly still exists in the middle-low-level of the troposphere over the western North Pacific. These circulation anomalies favor strengthened southwestern warm and moist flow and enhanced convergence of water vapor fluxes over southeastern China, leading to a significant increase in precipitation ( $\mathrm{Li}$ et al. 2013). In recent decades, southeastern China has experienced a significant decrease in precipitation in the boreal spring and has frequently suffered from persistent drought, and the droughts are consistent with anomalous overturning circulation and local anomalous descent motion (Xin et al. 2006; Sun and Yang 2012; Feng et al. 2014; Zhu et al. 2014; Li et al. 2016), but the long-term behavior of SPR precipitation in different reanalysis datasets remains unestablished.

Various reanalysis datasets have been extensively used in climatological studies. The reanalysis datasets are created via an unchanging data assimilation scheme and the most advanced operational numerical models. Under the process of data assimilation by observations, the atmospheric circulation in the reanalysis datasets is usually considered the optimal estimate. Comparing different datasets can provide robust knowledge on actual climate variability and climate change. For example, Bosilovich et al. (2008) used five reanalysis datasets to evaluate global precipitation in different regions. Lin et al. (2014) evaluated the changes in global monsoon precipitation by using multiple reanalysis datasets. Ma and Zhou (2016) compared seven reanalysis datasets and found that the tropical Pacific Walker 
circulation has strengthened and shifted westward in the recent decades. Previous studies often considered one or two reanalysis datasets as the optimal observation. At present, the uncertainty among different reanalysis datasets in describing the SPR change remains unknown. In this study, we use five reanalysis datasets to estimate uncertainties. We aim to answer the following questions: (1) how well can five reanalysis datasets capture climatology, the long-term trend and interannual variability of the SPR during the past 30 years? (2) Which components of the moisture budget dominate climatology and changes in the SPR? We will show that vertical moisture advection dominates the SPR variation, both JRA55 and ERAIM show relatively higher skill in reproducing the climatology and changes of the SPR and are thus recommended for climate variability and change studies.

The remainder of this paper is organized as follows. The observational datasets, five reanalysis datasets, and analysis methods are described in Sect. 2. In Sect. 3, we evaluate the performance of the five reanalysis datasets in reproducing the climatology and changes of SPR, and investigate the dominant component of the moisture budget for the aspect of climatology, the long-term trend and interannual variability of the SPR. Finally, a summary is given in Sect. 4.

\section{Data and methods}

\subsection{Data description}

The observational monthly precipitation data used in this study is the Global Precipitation Climatology Project (GPCP) version 2.2 dataset (Huffman et al. 1997; Adler et al. 2003). GPCP v2.2 is derived from a mix of satellite estimates of precipitation over ocean and land, and then adjusted by rain gauge measurements from land and atoll stations. It is available monthly and covers 1980-2012. The spatial resolution of GPCP v 2.2 is $2.5^{\circ} \times 2.5^{\circ}$. We also use rain gauge observation data over China to make the results based on GPCP convincible. Rain-gauge data of daily precipitation from 1980 to 2012 were obtained from the China Meteorological Administration (CMA; http://data.cma.cn/en). The CMA dataset contains 756 stations and is updated through recent years. To facilitate analysis, the rain gauge data were interpolated onto a $1.5^{\circ} \times 1.5^{\circ}$ grid .

The five reanalysis datasets used in this study include monthly precipitation, evaporation, surface pressure, vertical velocity, zonal and meridional components of wind and specific humidity:

1. Japanese 25-year reanalysis projects (JRA25; Onogi et al. 2007);

2. Japanese 55-year reanalysis projects (JRA55; Ebita et al. 2011);

3. European Centre for Medium-Range Weather Forecast (ECMWF) interim reanalysis (ERAIM; Dee et al. 2011);

4. European Centre for Medium-Range Weather Forecast (ECMWF) reanalysis of the twentieth century (ERA20C; Stickler et al. 2014);

5. National Centers for Environmental Prediction (NCEP) - Department of Energy (DOE) Atmospheric Model Intercomparison Project II (AMIP-II) reanalysis (NCEP2; Kanamitsu et al. 2002);

These reanalysis datasets differ in the atmospheric forecast model, data assimilation method, model resolution, and model physics. Their characteristics are summarized in Table 1. Each reanalysis dataset has a different time span but all cover our analysis period of 1980-2012. Results of each reanalysis are derived from their original horizontal resolution. The ensemble mean of five reanalysis datasets is calculated after each reanalysis dataset is interpolated into a global $2.5^{\circ} \times 2.5^{\circ}$ grid using conservative interpolation (using the local area-conservative

Table 1 Description of five reanalysis datasets

\begin{tabular}{|c|c|c|c|c|c|}
\hline & JRA25 & JRA55 & ERAIM & ERA20C & NCEP2 \\
\hline $\begin{array}{l}\text { Atmospheric forecast } \\
\text { model }\end{array}$ & $\begin{array}{l}\text { JMA global spectral } \\
\text { model }\end{array}$ & $\begin{array}{l}\text { JMA global spectral } \\
\text { model }\end{array}$ & $\begin{array}{l}\text { Integrated forecast } \\
\text { system }\end{array}$ & $\begin{array}{l}\text { Integrated forecast } \\
\text { system }\end{array}$ & $\begin{array}{l}\text { NCEP global } \\
\text { operational } \\
\text { model }\end{array}$ \\
\hline $\begin{array}{l}\text { Model horizontal reso- } \\
\text { lution }\end{array}$ & $\mathrm{T} 106(120 \mathrm{~km})$ & TL319 $(60 \mathrm{~km})$ & $\mathrm{T} 255(79 \mathrm{~km})$ & $\mathrm{T} 159(125 \mathrm{~km})$ & T62 (210 km) \\
\hline Vertical layer & 40 levels & 60 levels & 60 levels & 91 levels & 28 levels \\
\hline Time period & 1979-2012 & 1958-present & 1979-present & $1900-2010$ & 1979-present \\
\hline Satellite data processing & Radiances & Radiances & Radiances & - & Retrievals \\
\hline $\begin{array}{l}\text { Data assimilation } \\
\text { method }\end{array}$ & 3D-Var & 4D-Var & 4D-Var & 4D-Var & 3D-Var \\
\hline Organization & JMA & JMA & ECMWF & ECMWF & NCEP-DOE \\
\hline
\end{tabular}


binning method to interpolate the data from original grid to new rectilinear grid; Jones 1999).

In addition, we use the ENSO index derived from the CPC in National Oceanic and Atmospheric Administration (NOAA; information available online at http://www. cpc.noaa.gov/products/analysis_monitoring/ensostuff/ensoyears.shtml). Warm and cold periods are determined based on a threshold of $\pm 0.5^{\circ} \mathrm{C}$ for the 3-month running mean of Extended Reconstructed Sea Surface Temperature version 4 (ERSST v4; Huang et al. 2015a) anomalies in the Niño3.4 region $\left(5^{\circ} \mathrm{N}-5^{\circ} \mathrm{S}, 120^{\circ}-170^{\circ} \mathrm{W}\right)$, and based on the 1981-2010 period.

\subsection{Analysis methods}

To understand the mechanisms dominating SPR variation over southeastern China, we perform a moisture budget analysis following previous studies (Held and Soden 2006; Seager et al. 2010; Chou and Lan 2012; Huang et al. 2013; Feng and Zhou 2012; Lin et al. 2014; Ma and Zhou 2015). The moisture budget equation is (Eq. 1),

$\mathrm{P}=-\partial_{t}\langle\mathrm{q}\rangle-\nabla \cdot(\mathrm{q} \vec{V})+\mathrm{E}+\delta$

where $\mathrm{P}$ is precipitation, $\mathrm{E}$ is evaporation, $\mathrm{q}$ is specific humidity and $\vec{V}$ is wind vector. $\delta$ is a residual term including transient eddies (Trenberth and Guillemot 1995; Zhou and $\mathrm{Yu}$ 2005) and contributions from surface processes due to topography (Seager et al. 2010). All values in Eq. 1 are a 3 month mean of March-April-May (MAM). "〈〉" denotes a vertical mass integration through the whole troposphere (Eq. 2),

$\langle X\rangle=\frac{1}{g} \int_{p_{s}}^{p_{s}-p_{T}} X \mathrm{~d} p$

where $\mathrm{g}$ is gravitational acceleration, $p_{s}$ is surface pressure and $p_{T}$ is the pressure of the tropopause, taken as $100 \mathrm{hPa}$. $-\partial_{t}\langle\mathrm{q}\rangle$ in Eq. 1 is the time derivative of specific humidity $\mathrm{q}$, which can generally be ignored as its seasonal mean value is much smaller than other terms. $-\nabla \cdot(\mathrm{q} \vec{V})$ is the convergence of integrated moisture flux. According to the mass conservation equation, $-\nabla \cdot(\mathrm{q} \vec{V})$ can be divided into two terms (Chou and Lan 2012; Chou et al. 2013): a vertical moisture advection term $-\left\langle\omega \frac{\partial \mathrm{q}}{\partial \mathrm{p}}\right\rangle$ (simply written as

$-\langle w d q\rangle)$ and a horizontal moisture advection term $-\left\langle\vec{V}_{h} \cdot \nabla_{h} q\right\rangle$ (simply written as $-\langle v d q\rangle$ ). Therefore, Eq. 1 can be reformulated as (Eq. 3),

$P=-\left\langle\omega \partial_{p} q\right\rangle-\left\langle\vec{V}_{h} \cdot \nabla_{h} q\right\rangle+E+\delta$

where $\omega$ is the vertical pressure velocity and $\vec{V}_{h}$ is the horizontal wind vector. If $\omega$ is assumed to be zero at the surface and at the tropopause (i.e., $\left\langle\partial_{p} \omega q\right\rangle=0$ ), then from the mass conservation equation we can obtain $-\left\langle\omega \partial_{p} q\right\rangle=-\left\langle q \nabla_{h} \cdot \vec{V}_{h}\right\rangle$, so the vertical moisture advection is equal to the horizontal flow convergence of moisture term (Seager et al. 2010). Vertical moisture advection is mainly contributed by the convergence in the lower troposphere that promotes the vertical transport of moisture and then leads to rain formation.

To understand mechanisms that induce SPR anomalies, according to Eq. 3, the precipitation anomalies can be decomposed into (Eq. 4),

$\mathrm{P}^{\prime}=-\left\langle\omega \partial_{p} q\right\rangle^{\prime}-\left\langle\overrightarrow{V_{h}} \cdot \nabla_{h} \mathrm{q}\right\rangle^{\prime}+E^{\prime}+\delta^{\prime}$

Here, ()' represents the departure from climatology (see definition below). The residual term $\delta^{\prime}$ involves transient and nonlinear processes.

Following previous studies (Chou and Lan 2012; Chou et al. 2013; Huang et al. 2013; Ma and Zhou 2015), the changes of vertical moisture advection $-\left\langle\omega \partial_{p} q\right\rangle$ can be further divided as (Eq. 5),

$-\left\langle\omega \partial_{p} q\right\rangle^{\prime}=-\left\langle\bar{\omega} \partial_{p} q^{\prime}\right\rangle-\left\langle\omega^{\prime} \partial_{p} \bar{q}\right\rangle-\left\langle\omega^{\prime} \partial_{p} q^{\prime}\right\rangle$

where $(\bar{\omega})$ denotes the climatology from 1980 to 2012. The first term on the right of Eq. 5 represents changes in $\mathrm{q}$ with $\omega$ unchanged, conventionally called the thermodynamic component of $-\left\langle\omega \partial_{p} q\right\rangle^{\prime}$, contributed by the changes in water vapor (simply written as $\left.-\left\langle w d q^{\prime}\right\rangle\right)$; the second term involves changes in $\omega$ with q constant, associated with changes in pressure velocity, which is mainly induced by atmospheric circulation changes (simply written as $\left.-\left\langle w^{\prime} d q\right\rangle\right)$, and often called the dynamic component of $-\left\langle\omega \partial_{p} q\right\rangle^{\prime}$; the third term is a nonlinear term that is induced by changes in $\mathrm{q}$ and $\omega$, and is much smaller than the thermodynamic and dynamic components. As in a previous study (Chou et al. 2009, 2013; Ma and Zhou 2015), the contribution of horizontal moisture advection to precipitation changes is relatively small, so it is not divided into three terms as the vertical one. Therefore, Eq. 4 can be reformulated as Eq. 6,

$P^{\prime}=-\left\langle\bar{\omega} \partial_{p} q^{\prime}\right\rangle-\left\langle\omega^{\prime} \partial_{p} \bar{q}\right\rangle-\left\langle\vec{V}_{h} \cdot \nabla_{h} q\right\rangle^{\prime}+E^{\prime}+\delta^{\prime}$

\section{Results}

\subsection{Climatology of the SPR}

In this section, the mean state of the SPR and atmospheric water vapor transport from five reanalysis datasets from 
1980 to 2012 are evaluated. The GPCP precipitation shows that during MAM, the major rainfall center is in southeastern China, where precipitation intensity could be as large as $7 \mathrm{~mm} \mathrm{day}^{-1}$ (Fig. 1a). Furthermore, the precipitation in MAM accounts for approximately $30-35 \%$ of the annual accumulation (Fig. 1b), which means that the SPR contributes considerably to the total annual precipitation. Both observational rain gauge data and GPCP reveal coincident results with small disagreements, indicates that the results based on GPCP is reliable. We use GPCP to carry on our further study, because GPCP contains precipitation over ocean and the resolution of GPCP is more comparable

(a) JRA25

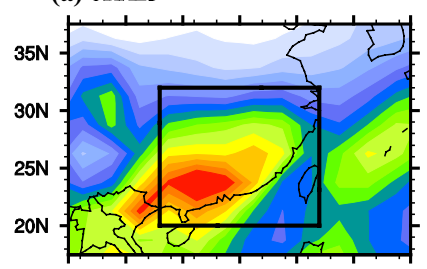

100E 105E 110E 115E 120E 125E 130E

(b) ERAMM

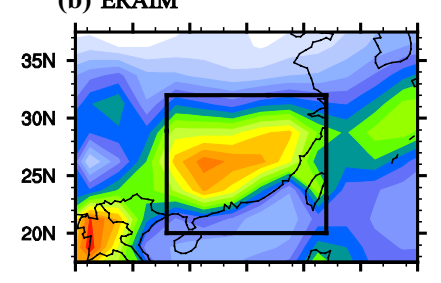

100E $105 \mathrm{E} \quad 110 \mathrm{E}$ 115E $120 \mathrm{E}$ 125E $130 \mathrm{E}$

(c) NCEP2

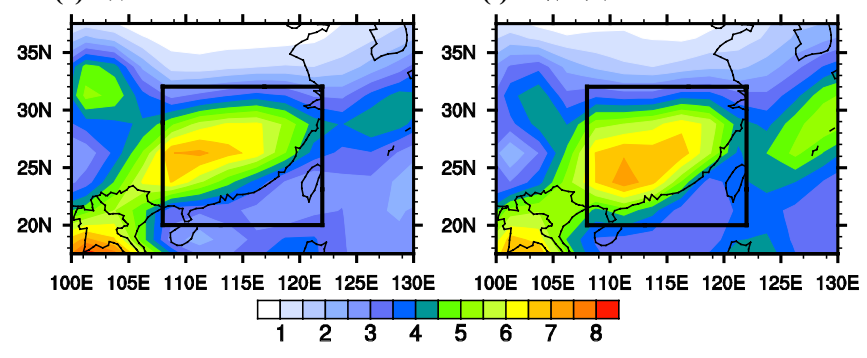

Fig. 2 The mean state of the SPR and bias over southeastern China a JRA25, b ERAIM, c NCEP2, d JRA55, e ERA20C, f the multi reanalysis ensemble mean results, $\mathbf{g}$ JRA25 bias, h ERAIM bias, with reanalysis datasets. The box $\left(20-32^{\circ} \mathrm{N}, 108-122^{\circ} \mathrm{E}\right)$ in Fig. 1 enclosing the major rainfall center is used to perform the moisture budget analysis.

The climatological mean of the SPR over southeastern China for the five reanalysis datasets and their ensemble mean are shown in Fig. 2. Table 2 shows the area-averaged precipitation intensity $\left(\mathrm{mm} \mathrm{day}^{-1}\right)$ and pattern correlation coefficients (PCCs) over the SPR major rainfall center for the five reanalysis datasets. The five reanalysis datasets reproduce the spatial patterns of GPCP reasonably well. PCCs are $0.66,0.61,0.62,0.49$ and 0.52 for JRA25, JRA55, ERAIM, ERA20C and NCEP2, respectively. All (g) Bias_JRA25

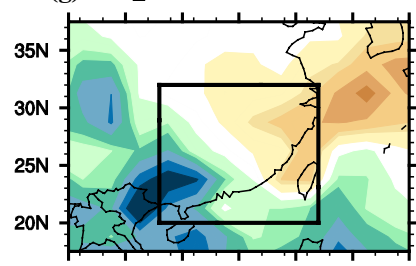

100E 105E 110E 115E 120E 125E 130E

(h) Bias_ERAIM

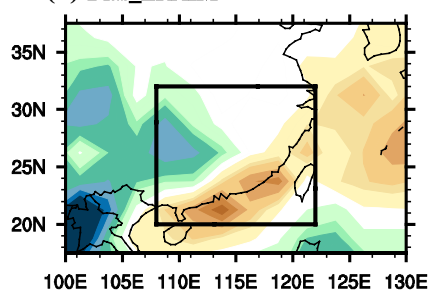

(i) Bias_NCEP2 (j) Bias_JRA55

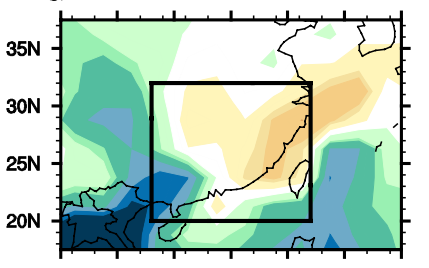

1O0E 105E 110E 115E 120E 125E $130 \mathrm{E}$

(k) Bias_ERA20C

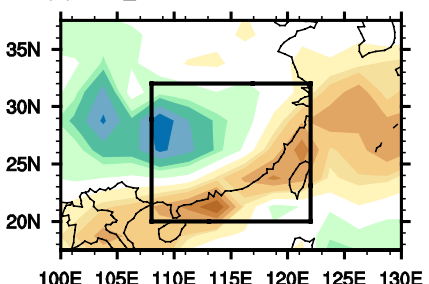

(l) Bias_Ensemble

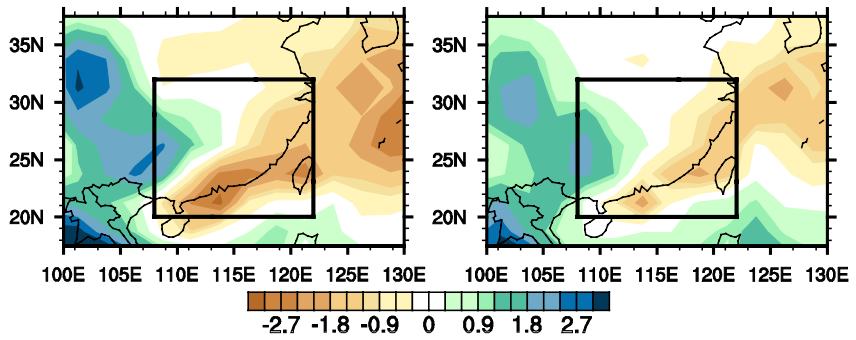

i NCEP2 bias, $\mathbf{j}$ JRA55 bias, $\mathbf{k}$ ERA20C bias, $\mathbf{l}$ the multi reanalysis ensemble mean bias. The bias is calculated as the difference with GPCP. The rectangle indicates the major rainfall center

Table 2 The area-averaged precipitation intensity $\left(\mathrm{mm} \mathrm{day}^{-1}\right)$ and pattern correlation coefficients (PCCs) over the SPR major rainfall center from five reanalysis datasets and the ensemble mean for climatology and the El Niño decaying spring (i.e., 1983, 1987, 1992 and 1998)

\begin{tabular}{|c|c|c|c|c|c|c|c|}
\hline & GPCP & JRA25 & JRA55 & ERAIM & ERA20C & NCEP2 & Ensemble \\
\hline \multicolumn{8}{|l|}{ Climatology } \\
\hline Intensity $\left(\mathrm{mm} \mathrm{day}^{-1}\right)$ & 5.25 & 5.32 & 5.22 & 4.93 & 4.68 & 4.54 & 4.94 \\
\hline PCCs & - & 0.66 & 0.61 & 0.62 & 0.49 & 0.52 & 0.68 \\
\hline \multicolumn{8}{|c|}{ During El Niño decaying spring } \\
\hline Intensity $\left(\mathrm{mm} \mathrm{day}^{-1}\right)$ & 1.26 & 1.52 & 1.28 & 1.20 & 1.01 & 1.74 & 1.31 \\
\hline PCCs & - & 0.67 & 0.59 & 0.70 & 0.53 & 0.19 & 0.64 \\
\hline
\end{tabular}


five reanalysis datasets show a westward shift of the rainfall center. The western boundary (defined as the longitude of the $5 \mathrm{~mm} \mathrm{day}^{-1}$ contour line) in the reanalysis datasets extends to almost $105^{\circ} \mathrm{E}$, approximately $5^{\circ}$ westward compared to observation $\left(\sim 110^{\circ} \mathrm{E}\right)$. In addition, ERAIM, ERA20C and NCEP2 have an obvious northward shift in reproducing the spring precipitation. The JRA55 is superior in reproducing rainfall intensity averaged over the major rainfall center among the five reanalysis datasets. The ensemble mean shows the best performance in reproducing rainfall spatial distribution $(\mathrm{PCC}=0.68)$, higher than any single reanalysis dataset.

The climatological water vapor transport that contributes to the SPR is shown in Fig. 3. All five reanalysis datasets indicate that there are two main channels remotely supplying water vapor for the SPR over southeastern China. One is the water vapor transported by strong westerly wind flow over the southern Tibetan Plateau (TP); the other water vapor source is from southwestern wind flow over the western North Pacific (WNP). These two moisture sources merge approximately at $110^{\circ} \mathrm{E}$ and converge over southeastern China, providing adequate water vapor for the SPR. The spatial distribution of integrated water vapor convergence is similar to that of precipitation.

To understand the mechanisms dominating local SPR precipitation, the area-averaged precipitation, as well as other components of the moisture budget in MAM over the major rainfall center is shown in Fig. 4. All five reanalysis datasets show that locally the SPR is primarily contributed by evaporation and vertical moisture advection component. The pattern of evaporation is uniform with an intensity of approximately $3 \mathrm{~mm}$ day $^{-1}$ (Fig. 4c). Four reanalysis datasets (JRA25, JRA55, ERAIM and ERA20C) show similar results in reproducing evaporation, except for NCEP2. The evaporation in NCEP2 is approximately $0.8 \mathrm{~mm} \mathrm{day}^{-1}$ stronger than that of the other four reanalysis datasets (Fig. 4a). The pattern of vertical moisture advection is uneven, anchored by the "Nanling" $\left(24-26.5^{\circ} \mathrm{N}, 110-116^{\circ} \mathrm{E}\right)$ and "Wuyi" $\left(25-29^{\circ} \mathrm{N}, 116-119^{\circ} \mathrm{E}\right)$ Mountains (Fig. 4d), and similar to the precipitation distribution, indicating that the "Nanling-Wuyi" Mountains in southeastern China can enhance the convergence of water vapor flux and then
Fig. 3 The vertically integrated climate mean spring water vapor transport flux (vectors, unit: $\left.\mathrm{kg} \mathrm{m}^{-1} \mathrm{~s}^{-1}\right)$ and divergence (shading areas, unit: $\left.10^{-4} \mathrm{~kg} \mathrm{~m}^{-2} \mathrm{~s}^{-1}\right)$ in reanalysis datasets: a JRA25, b JRA55, c ERAIM, d ERA20C, e NCEP2, f the multi reanalysis ensemble mean results. The masked regions denote topography higher than $1200 \mathrm{~m}$
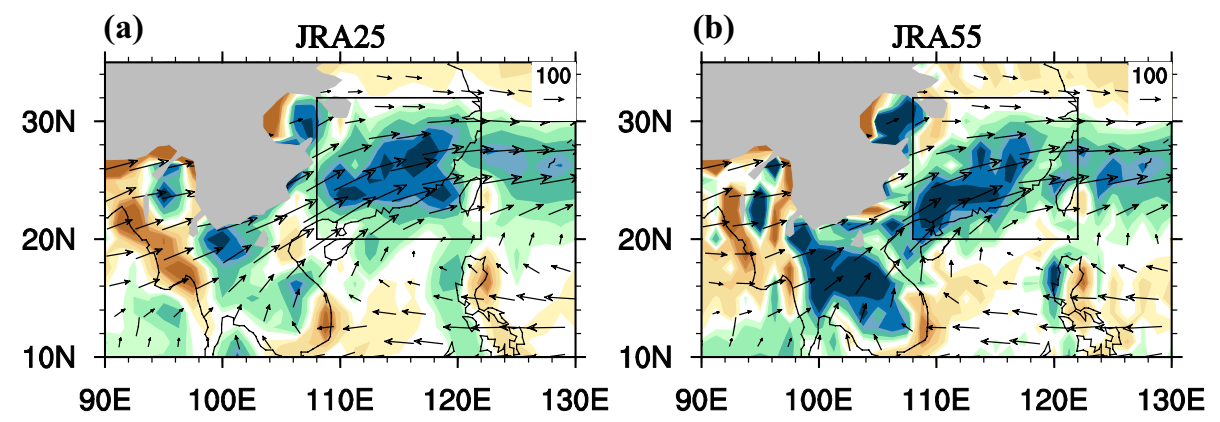

(c)

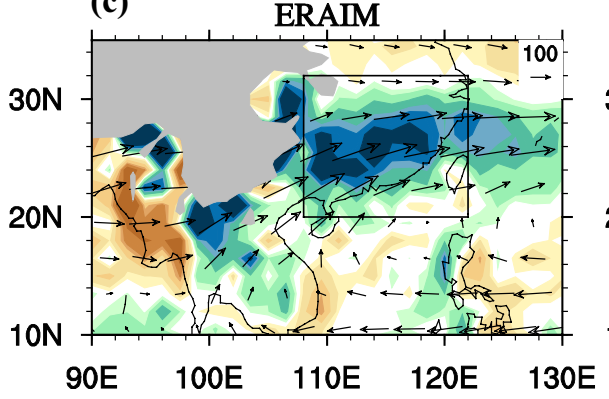

(d)

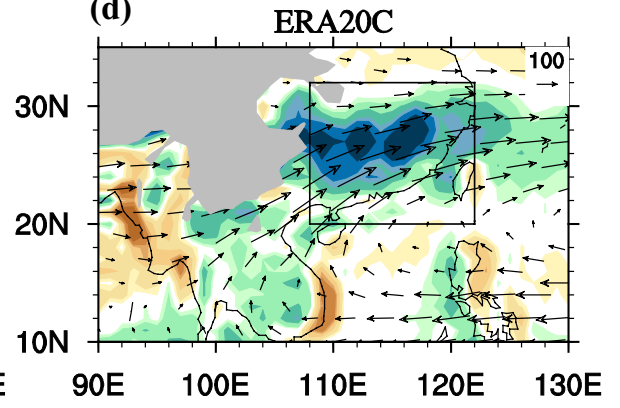

(e) NCEP2
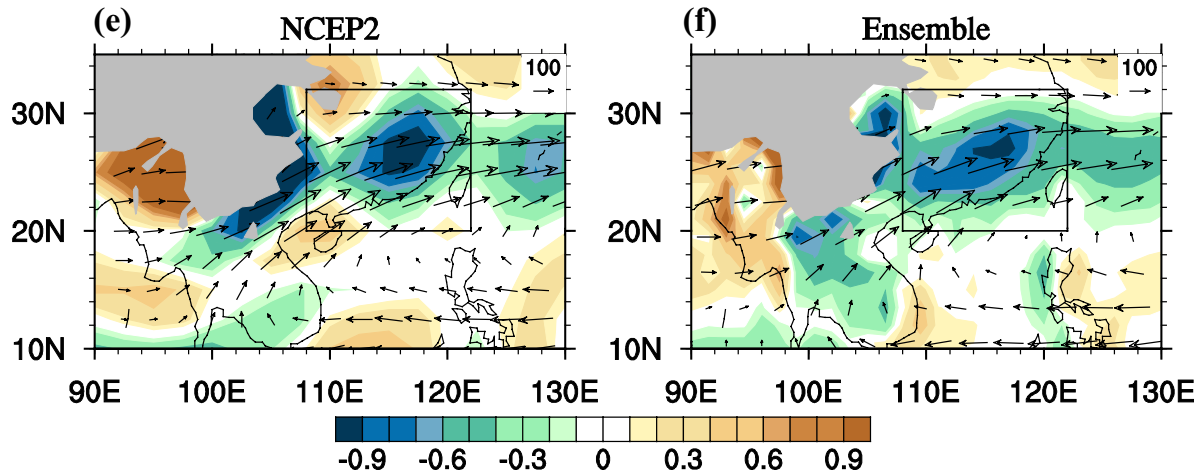
Fig. 4 Climatological SPR precipitation and other moisture budget components in GPCP data and reanalysis datasets (unit: $\mathrm{mm} \mathrm{day}^{-1}$ ): a moisture budget components averaged over the major rainfall center, $\mathbf{b}$ multi reanalysis ensemble mean precipitation, $\mathbf{c}$ multi reanalysis ensemble mean evaporation, $\mathbf{d}$ multi reanalysis ensemble mean vertical moisture advection
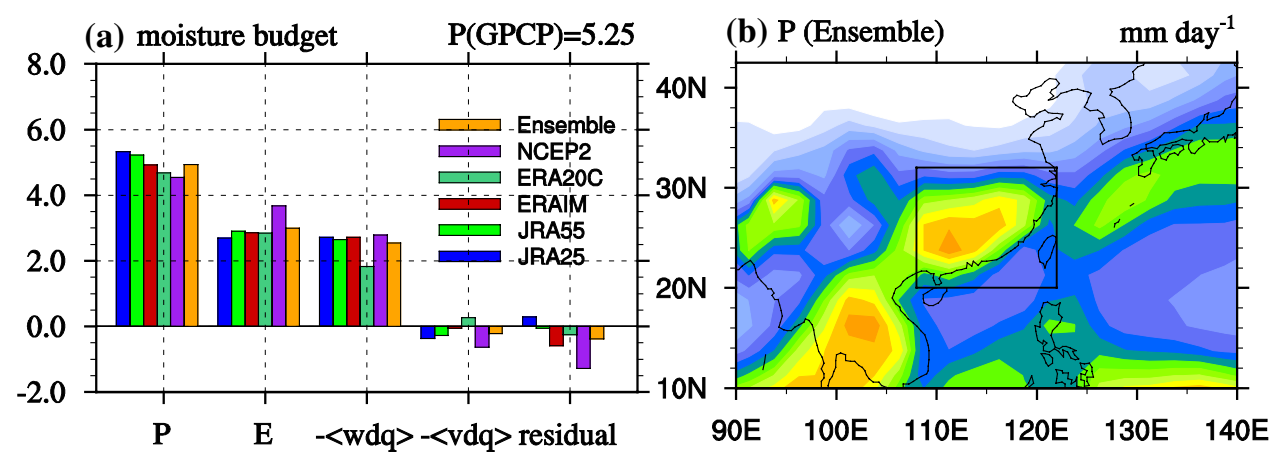

(c) $\mathrm{E}$ (Ensemble)

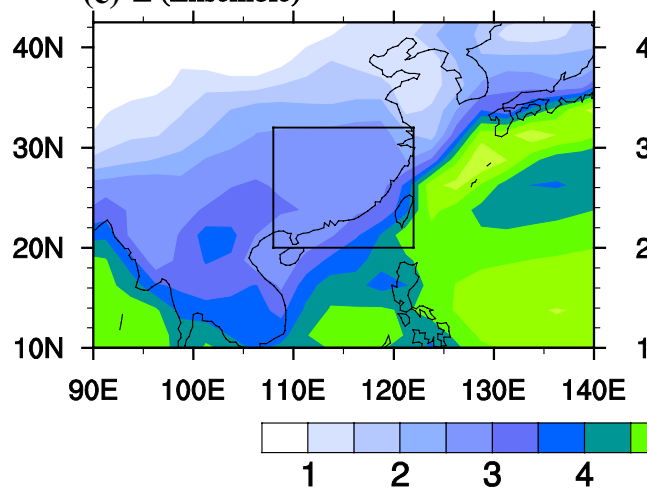

(d) $-<w d q>$ (Ensemble)

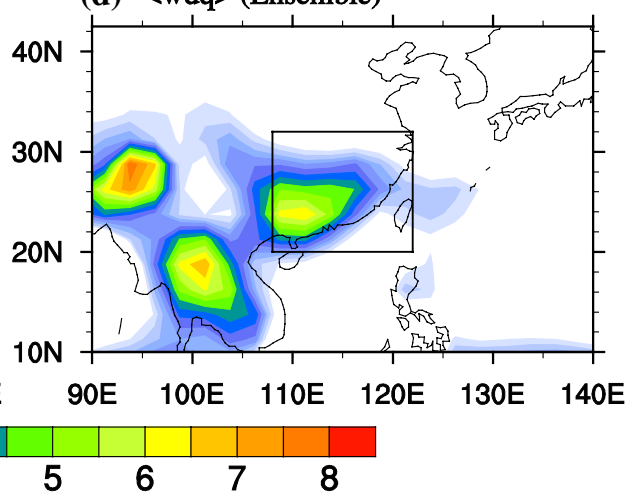

favor SPR formation. The vertical moisture advection in ERA20C is approximately $0.9 \mathrm{~mm} \mathrm{day}^{-1}$ weaker than that of the other four reanalysis datasets (Fig. 4a). The horizontal moisture advection and residual components contribute little to the total SPR precipitation.

\subsection{The long-term trend and interannual variability of the SPR}

\subsubsection{The long-term trend of the SPR}

The long-term trend of the SPR precipitation shows a significant decrease (Fig. 5a, b). In observations, southeastern China has experienced a significant drying trend over the past 33 years (1980-2012). The land and coastline in southeastern China have suffered the most obvious decrease, with most of this region exhibiting a significant negative trend of more than $0.6 \mathrm{~mm} \mathrm{day}^{-1}(10 \text { year })^{-1}$. The patterns of the trend derived from the ensemble mean of the five reanalysis datasets are consistent with observation. However, more regions in southeastern China experienced a decreasing trend in the reanalysis datasets compared to the observation.

The time series of the SPR precipitation anomalies averaged over the major rainfall center are shown in Fig. 5e. All five reanalysis datasets are consistent with observation. The observed SPR precipitation shows a negative tendency of $-0.38 \mathrm{~mm} \mathrm{day}^{-1}(10 \text { year })^{-1}$ at a $5 \%$ significance level from 1980 to 2012 . The trend is $-0.79,-0.46$,
-0.41 and $-0.65 \mathrm{~mm} \mathrm{day}^{-1}(10 \text { year })^{-1}$ in the JRA25, JRA55, ERAIM and NCEP2 reanalysis datasets, respectively, all exceeding the $1 \%$ significance level (Table 3 ). The trend in ERA20C shows a weaker decreasing trend $\left[-0.26 \mathrm{~mm} \mathrm{day}^{-1}(10 \text { year })^{-1}\right]$, which is still statistically significant at the $10 \%$ level. Both JRA55 and ERAIM are more similar to observation than the other reanalysis datasets (Table 3 ). In additional to the long-term trend, observation also shows a robust year by year variability. JRA55 shows the highest correlation coefficient (0.96) with observation, and the ensemble mean of five reanalysis datasets also shows a relatively high correlation coefficient (0.92). NCEP2 shows the lowest skill among the datasets, but the correlation coefficient $(0.78)$ is still statistically significant at the $1 \%$ level (Table 3 ).

To better understand the long-term trend of SPR precipitation, we performed a moisture budget analysis to examine the trend of each term in the moisture budget. The linear trend of SPR precipitation and other moisture budget components are shown in Fig. 6. The evaporation in all five reanalysis datasets shows a weak increasing trend from 1980 to 2012. The decreasing trend of SPR precipitation is dominated by change in the vertical moisture advection, which shows a significant decreasing trend in all five reanalysis datasets. The PCC between these two terms for the ensemble mean is 0.83 . We decompose the change in vertical moisture advection into three terms (Eq. 5), and find that the dynamic term dominates the change in vertical moisture advection. The spatial pattern of the linear trend for the 

reanalysis datasets. The linear trend of SPR precipitation [unit: $\mathrm{mm} \mathrm{day}^{-1}(10 \text { year })^{-1}$ ] for 1980 to 2012 in $\mathbf{a}$ GPCP and $\mathbf{b}$ the multi reanalysis ensemble mean with regions of $>90 \%$ confidence level marked by black dots. The standard deviations of SPR precipitation (unit: $\mathrm{mm} \mathrm{day}^{-1}$ ) for 1980 to 2012 in c GPCP and $\mathbf{d}$ the multi reanalysis ensemble mean. $\mathbf{e}$ The time series of SPR precipitation anomalies in GPCP and reanalysis datasets (unit: $\mathrm{mm} \mathrm{day}^{-1}$ )
Fig. 5 The changes of the SPR precipitation in GPCP data and (a) P_trend(GPCP)

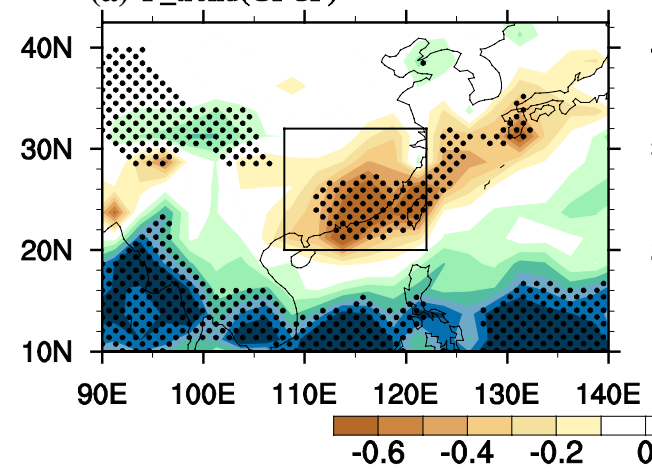

(c) P_stddev(GPCP)

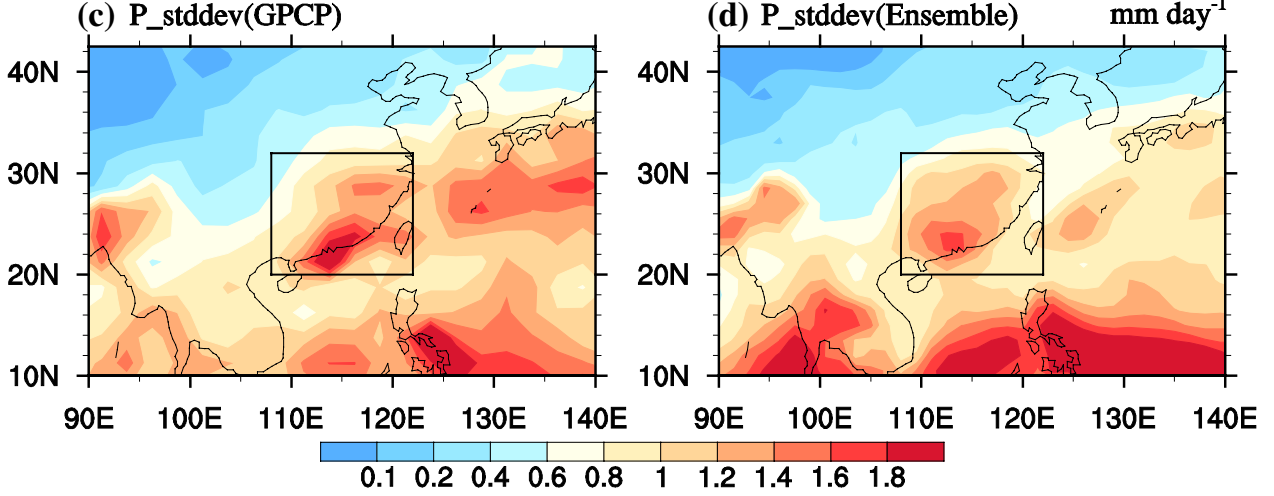

(e) P_anomalies (d) P_stddev(Ensemble)
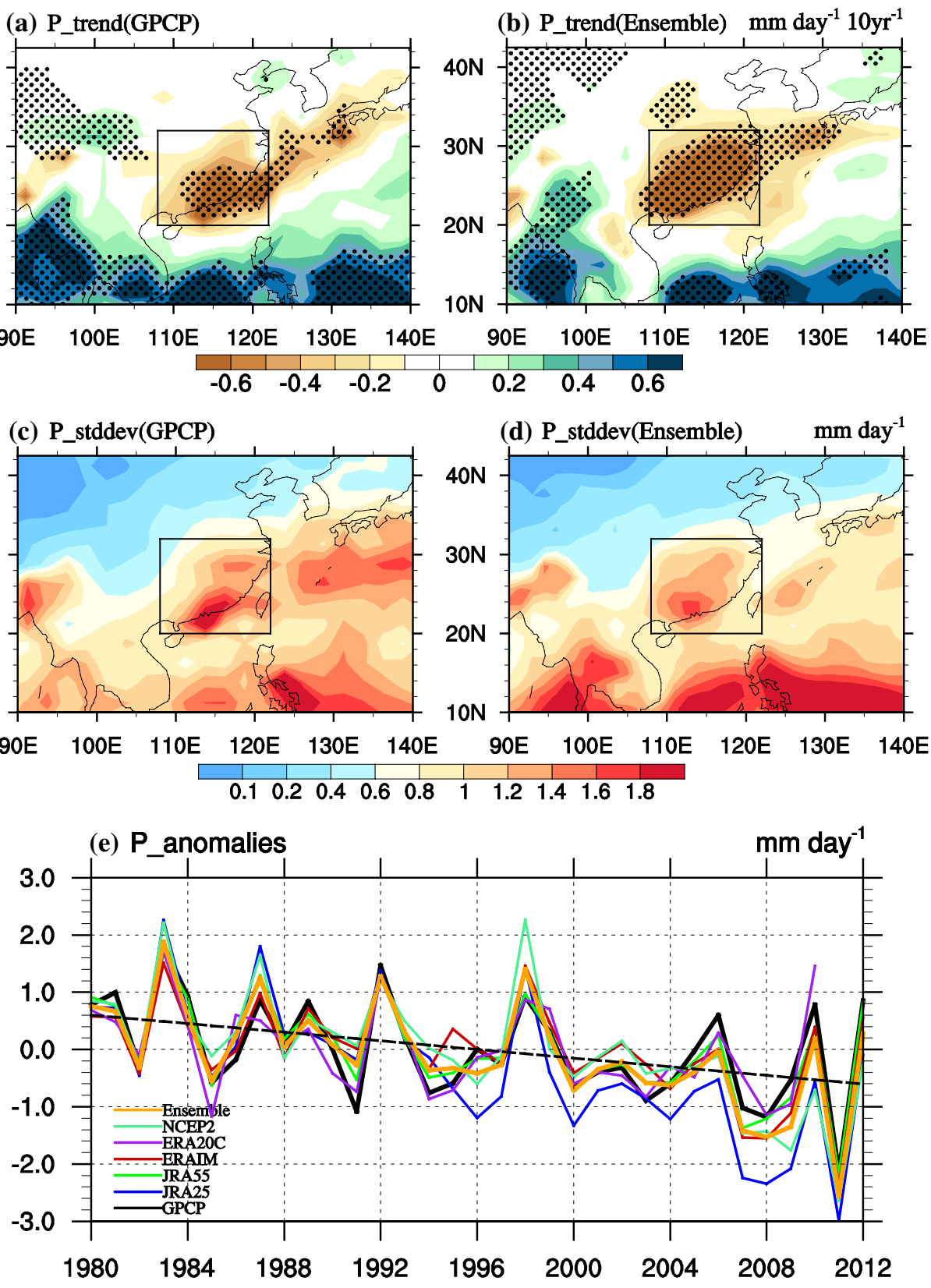

Table 3 The correlation coefficients between the time series of precipitation anomalies in observation and five reanalysis datasets and the ensemble mean (unit: $\mathrm{mm} \mathrm{day}^{-1}$ ) as well as the long-term trend [unit: $\left.\mathrm{mm} \mathrm{day}^{-1}(10 \text { year })^{-1}\right]$ in SPR precipitation

\begin{tabular}{|c|c|c|c|c|c|c|c|}
\hline & GPCP & JRA25 & JRA55 & ERAIM & ERA20C & NCEP2 & Ensemble \\
\hline \multicolumn{8}{|c|}{ Trend and statistical significance (1980-2012) } \\
\hline Trend & -0.38 & -0.79 & -0.46 & -0.41 & -0.26 & -0.65 & -0.51 \\
\hline Confidence level $(\%)$ & 95 & 99 & 99 & 99 & 90 & 99 & 99 \\
\hline \multicolumn{8}{|c|}{ Correlation coefficients between observation and five reanalysis datasets } \\
\hline Before detrending & - & 0.84 & 0.96 & 0.88 & 0.89 & 0.78 & 0.92 \\
\hline After detrending & _- & 0.83 & 0.96 & 0.85 & 0.88 & 0.74 & 0.91 \\
\hline
\end{tabular}


Fig. 6 The linear trend of the SPR precipitation and other moisture budget components [unit: $\mathrm{mm} \mathrm{day}^{-1}(10 \text { year })^{-1}$ ] for 1980 to 2012. a The linear trend of moisture budget components averaged over the major rainfall center. Shading areas in b-d show the spatial distributions of the major moisture budget components trend in the ensemble mean of the multi reanalysis datasets: $\mathbf{b}$ the trend of precipitation, $\mathbf{c}$ the trend of vertical moisture advection $(-\langle w d q\rangle), \mathbf{d}$ the trend of dynamic component $\left(-\left\langle\mathrm{w}^{\prime} \mathrm{dq}\right\rangle\right)$, areas of $>90 \%$ confidence level are marked by black dots
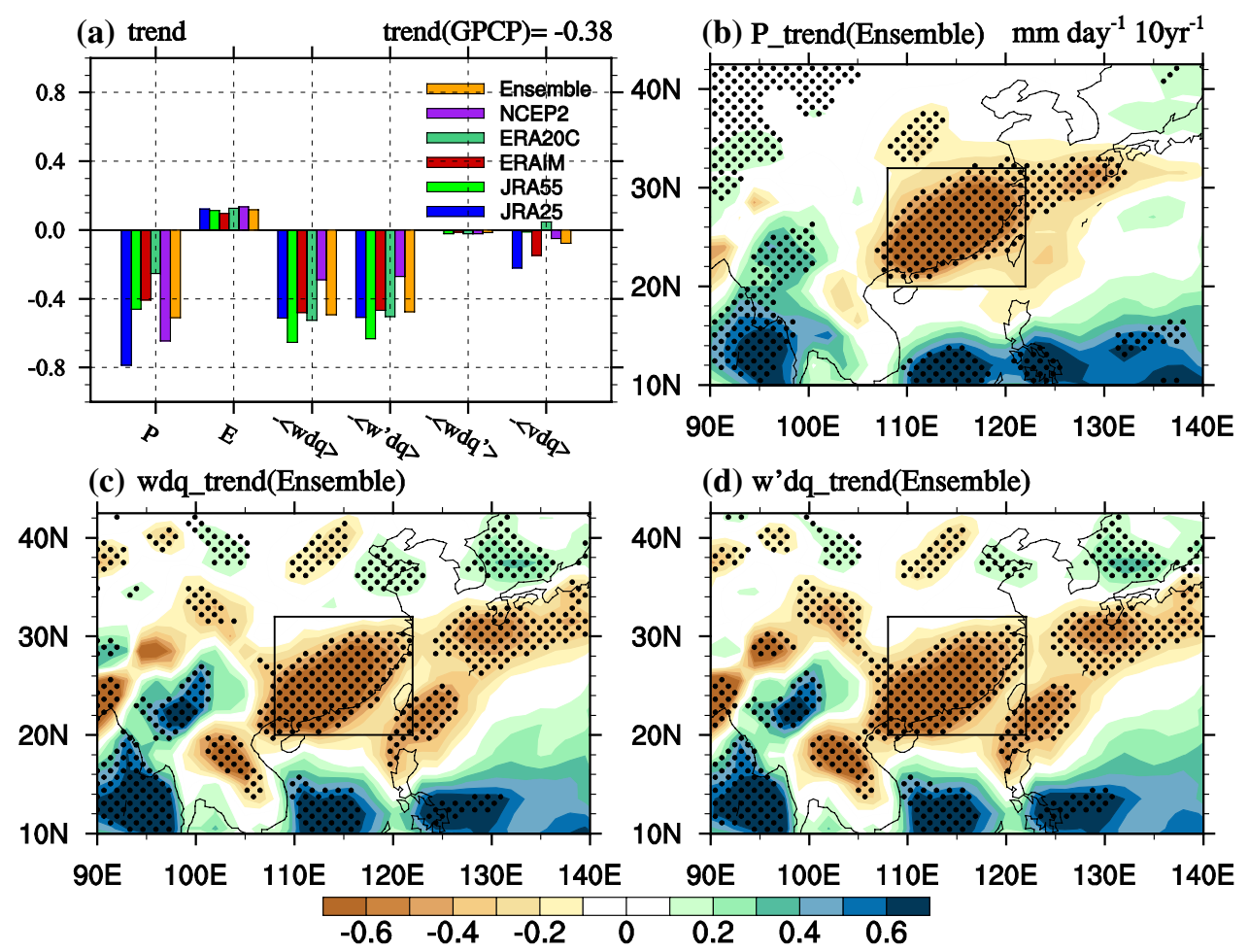

dynamic term matches that of vertical moisture advection, as evidenced by a high PCC of 0.99 . Thus, the decreasing trend of SPR precipitation is induced by atmospheric circulation changes.

The time series of vertical moisture advection anomalies and thermodynamic and dynamic components are shown in Fig. 7. The vertical moisture advection anomalies term in the ensemble mean of the five reanalysis datasets shows a negative trend at a rate of $-0.50 \mathrm{~mm} \mathrm{day}^{-1}(10 \text { year })^{-1}$ from 1980 to 2012, exceeding the $1 \%$ significance level (Fig. 7a). We further examine the long-term trends of the thermodynamic and dynamic components. The dynamic term shows a negative trend of $-0.48 \mathrm{~mm} \mathrm{day}^{-1}(10 \text { year })^{-1}$ (Fig. 7b), but the thermodynamic term shows no significant long-term trend (Fig. 7c). Hence, the negative long-term trend of SPR from 1980 to 2012 is due to a weakening of circulation.

The weakening of dynamic component is also evidenced by the vertical pressure velocity of $500 \mathrm{hPa}$. All five reanalysis datasets show a weakening trend from 1980 to 2012 at the $1 \%$ significance level (Fig. 7d). The weakening of ascending motion is consistent with the decreasing trend of SPR precipitation. Then we further examine the large-scale atmospheric circulation associated with the weakening of ascending motion (Fig. 7e). The anomalous descending motions are over southeastern China and surrounding regions, the long-term linear trend of $\omega 500$ is around $0.03 \mathrm{~Pa} \mathrm{~s}^{-1}$ (33 year) ${ }^{-1}$ over these regions, corresponding with the low-level northwesterly anomalies over eastern China and South China Sea. There are studies (Li et al. 2016) suggested that the intensified latent heating released by the convection over South China Sea and the Philippine Sea could build and reinforce the heat-induced atmospheric circulation, suppress the ascending motion over southeastern China, thus leads to the decreasing trend of the SPR.

\subsubsection{Interannual variability of the SPR}

Regarding interannual variability, standard deviations of the SPR over southeastern China are shown in Fig. 5c, d. In observation, the spatial distribution of the standard deviation is along the coastline of southeastern China and the center is located at the Pearl River Estuary (approximately $22.5^{\circ} \mathrm{N}, 113.7^{\circ} \mathrm{E}$ ). The maximum value in the center of standard deviations is over $1.8 \mathrm{~mm} \mathrm{day}^{-1}$ in observation (Fig. 5c). The pattern of the ensemble mean is similar to observation, but with a weaker intensity (Fig. 5d).

ENSO is an important driving factor for the interannual variability of the SPR over southeastern China (Wan et al. 2008; Feng and Li 2011; Li et al. 2013). The influences of El Niño and La Niña are asymmetric, and only the positive or warm events have significant influences on the SPR (Feng and Li 2011). To investigate the influence of El Niño on the SPR, we select 4 El Niño years (i.e., 1983, 1987, 1992 and 1998; only in these 4 years the Niño3.4 index was higher than $+1.0^{\circ} \mathrm{C}$ in preceding winter and could still reach up to $+1.0^{\circ} \mathrm{C}$ during the decaying spring) based on 

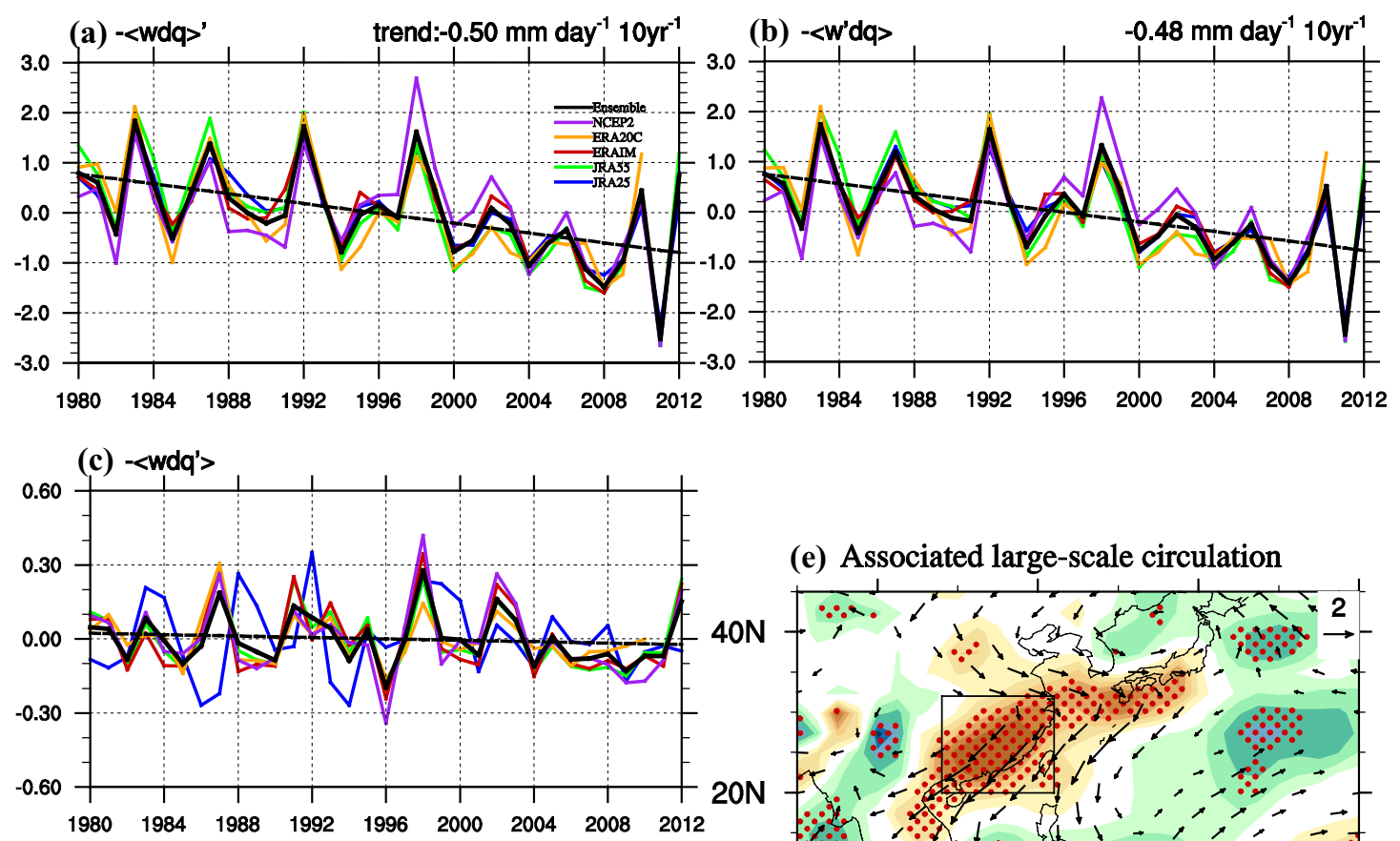

(e) Associated large-scale circulation

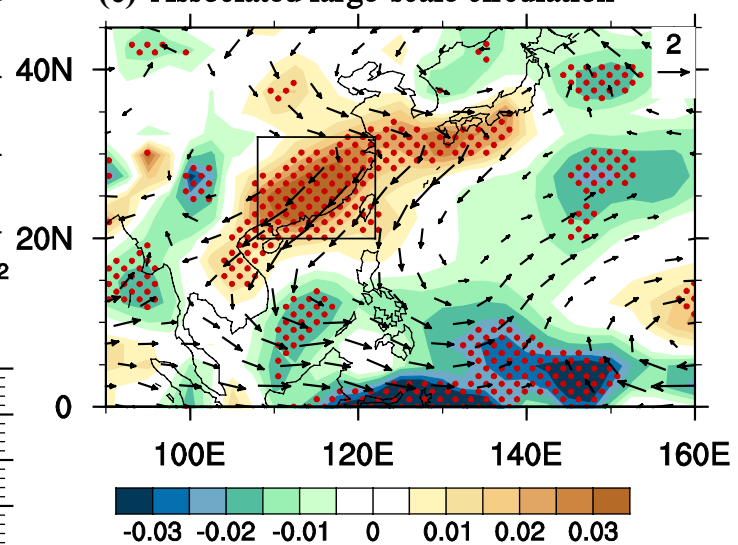

Fig. 7 a The time series of vertical moisture advection anomalies $\left(-\langle\mathrm{wdq}\rangle^{\prime}\right)$ averaged over the major rainfall center from 1980 to 2012 (unit: $\mathrm{mm} \mathrm{day}^{-1}$ ); $\mathbf{b}$ and $\mathbf{c}$ are the same as a, but for dynamic $\left(-\left\langle\mathrm{w}^{\prime} \mathrm{dq}\right\rangle\right)$ and thermodynamic $\left(-\left\langle\mathrm{wdq}^{\prime}\right\rangle\right)$ components; $\mathbf{d}$ the time series of vertical pressure velocity anomalies at $500 \mathrm{hPa}\left(\omega^{\prime} 500\right.$; unit:

the Niño3.4 index (Trenberth 1997) to make a composite analysis. Per observation, the spatial distributions of composite precipitation anomalies (Fig. 8b) are consistent with the standard deviation (Fig. 5c, PCC is up to 0.87). The PCCs are 0.67, 0.59, 0.70, 0.53 and 0.19 for JRA25, JRA55, ERAIM, ERA20C and NCEP2, respectively (Table 2). The ensemble mean of the five reanalysis datasets captures the precipitation anomalies with a PCC value of 0.64 (Fig. 8c).

To understand which processes mainly contribute to positive precipitation anomalies, we examine each component of the moisture budget anomalies in an El Niño decaying spring (Fig. 8a). The PCC between the anomalies of vertical moisture advection and precipitation is 0.77 , so the positive precipitation anomalies in the El Niño decaying $\left.-10^{-2} \mathrm{~Pa} \mathrm{~s}^{-1}\right)$; e the large-scale circulation pattern associated with the long-term trend of vertical motion, the shading areas indicate spatial pattern of the linear trend for $\omega 500$ [unit: $\mathrm{Pa} \mathrm{s}^{-1}$ (33) year ${ }^{-1}$ ], areas of $>90 \%$ confidence level are marked by red dots. The vectors indicate the long-term linear trend of $850 \mathrm{hPa}$ wind [unit: $\mathrm{m} \mathrm{s}^{-1}$ (33) year ${ }^{-1}$ ]

spring are mainly caused by the positive vertical moisture advection anomalies (Fig. 8d). The changes in horizontal moisture advection are relatively small and show negative anomalies. The contribution of evaporation is negligible. We further examine the thermodynamic and dynamic components of vertical moisture advection. Both have positive contributions, but the dynamic component dominates (Fig. 8a). Thus, the positive precipitation anomalies in the El Niño decaying spring are mainly caused by the enhancement of upward motion.

What is the large-scale circulation pattern that controls the enhanced upward motion? The vertically integrated water vapor transport flux and its convergence in the El Niño decaying spring are shown in Fig. 9. The anomalous lower-tropospheric anticyclone over the western North 


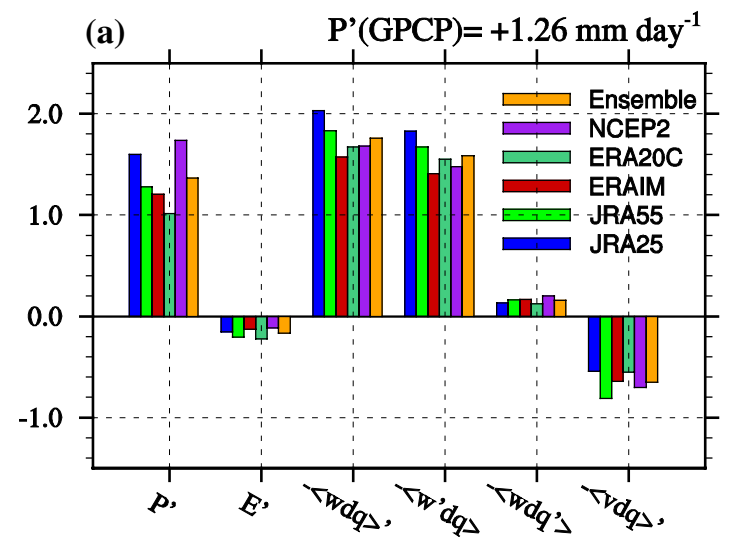

(c) P' (Ensemble)

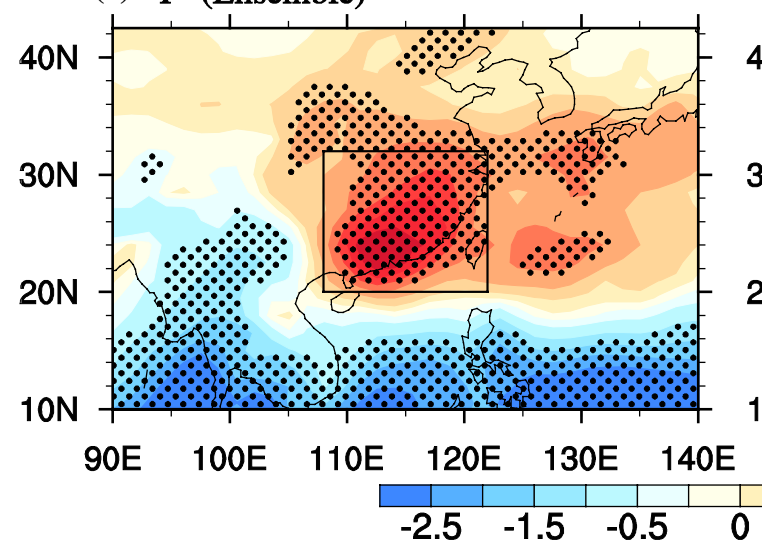

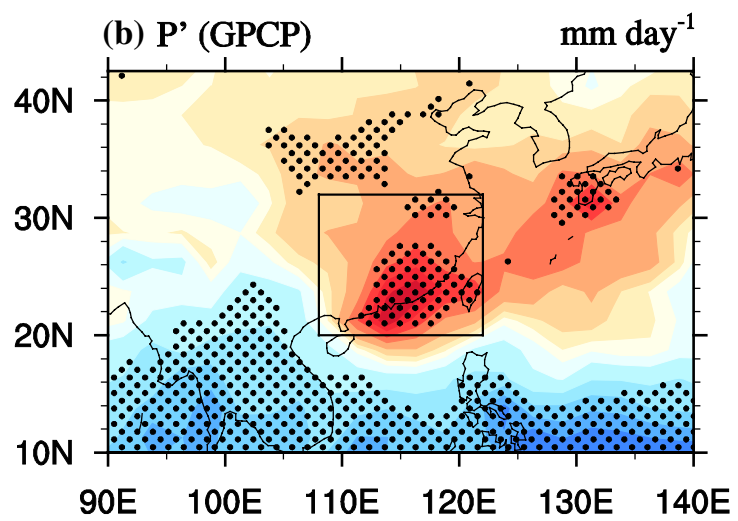

(d) $-<$ wdq $>$ ' (Ensemble)

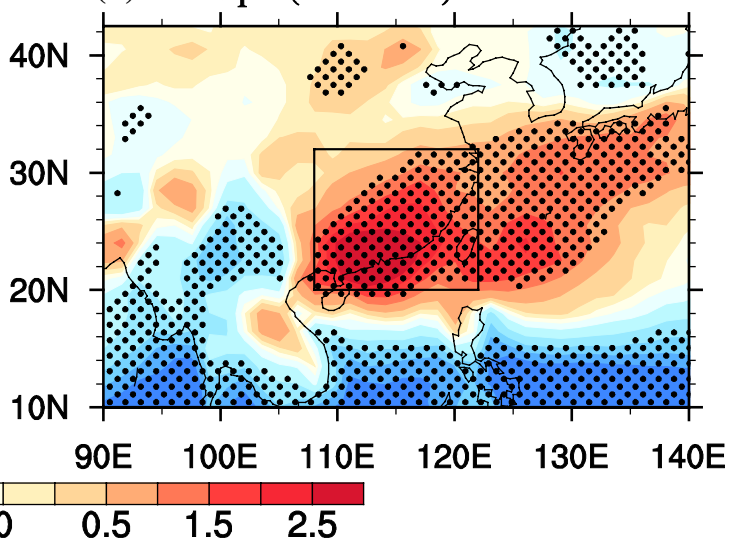

Fig. 8 Precipitation and other components of the moisture budget anomalies in the El Niño decaying springs (unit: $\mathrm{mm} \mathrm{day}^{-1}$ ): a moisture budget anomalies averaged over the major rainfall center; $\mathbf{b}$ the spatial distribution of precipitation anomalies in GPCP data; $\mathbf{c}$ the same as $\mathbf{b}$, but for precipitation anomalies in the ensemble mean of multi reanalysis datasets; $\mathbf{d}$ the anomalies of vertical moisture advection $\left(-\langle w d q\rangle^{\prime}\right)$ in the ensemble mean of multi reanalysis datasets. Areas of $>90 \%$ confidence level are marked by black dots
Pacific (i.e., WNPAC) establishes and matures during El Niño years, resulting from a Rossby-wave response to suppressed convective heating, coupled with in situ ocean surface cooling and the subsidence forced remotely by the central Pacific warming (Wang et al. 2000; Wang and Zhang 2002). The convergence of water vapor transport flux in JRA55 has an evident center around the Pearl River Estuary, consistent with the spatial distribution of positive precipitation anomalies (Fig. 9b). Although the five reanalysis datasets exhibit a spread in simulating the convergence of water vapor transport flux, they are highly consistent in reproducing the WNPAC in the El Niño decaying spring (Fig. 9). All five reanalysis datasets feature a strengthened southwestern water vapor transport at the western flank of the WNPAC, which brings more moisture from the tropical Pacific and South China Sea and converges over southeastern China, and then leads to more precipitation in these regions.

\section{Summary and discussion}

\subsection{Summary}

The SPR over southeastern China is a unique climatic phenomenon before onset of the East Asian summer monsoon. In this study, we analyze the climatology, the long-term trend and interannual variability of the SPR derived from five reanalysis datasets compared to GPCP data. The moisture budget is diagnosed to better understand the formation and changes of the SPR. The major results are summarized in Fig. 10. The main findings are summarized as follows:

1. Climatology (see Fig. 10a for a summary of major results): All five reanalysis datasets could reproduce the spatial distributions reasonably well, with PCCs of 0.68 [0.49-0.66] (meaning a PCC of 0.68 for the ensemble mean, and PCCs ranging from 0.49 to 0.66 in the datasets). However, precipitation in reanalysis datasets has a northward and westward shift compared to observa- 
Fig. 9 Composite vertically integrated spring water vapor transport flux (vectors, unit: $\mathrm{kg} \mathrm{m}^{-1} \mathrm{~s}^{-1}$ ) and divergence anomalies (shading areas, unit: $10^{-4} \mathrm{~kg} \mathrm{~m}^{-2} \mathrm{~s}^{-1}$ ) in the El Niño decaying springs: a JRA25, b JRA55, c ERAIM, d ERA20C, e NCEP2, f multi reanalysis ensemble mean results. The masked areas mean that topography is higher than $1200 \mathrm{~m}$
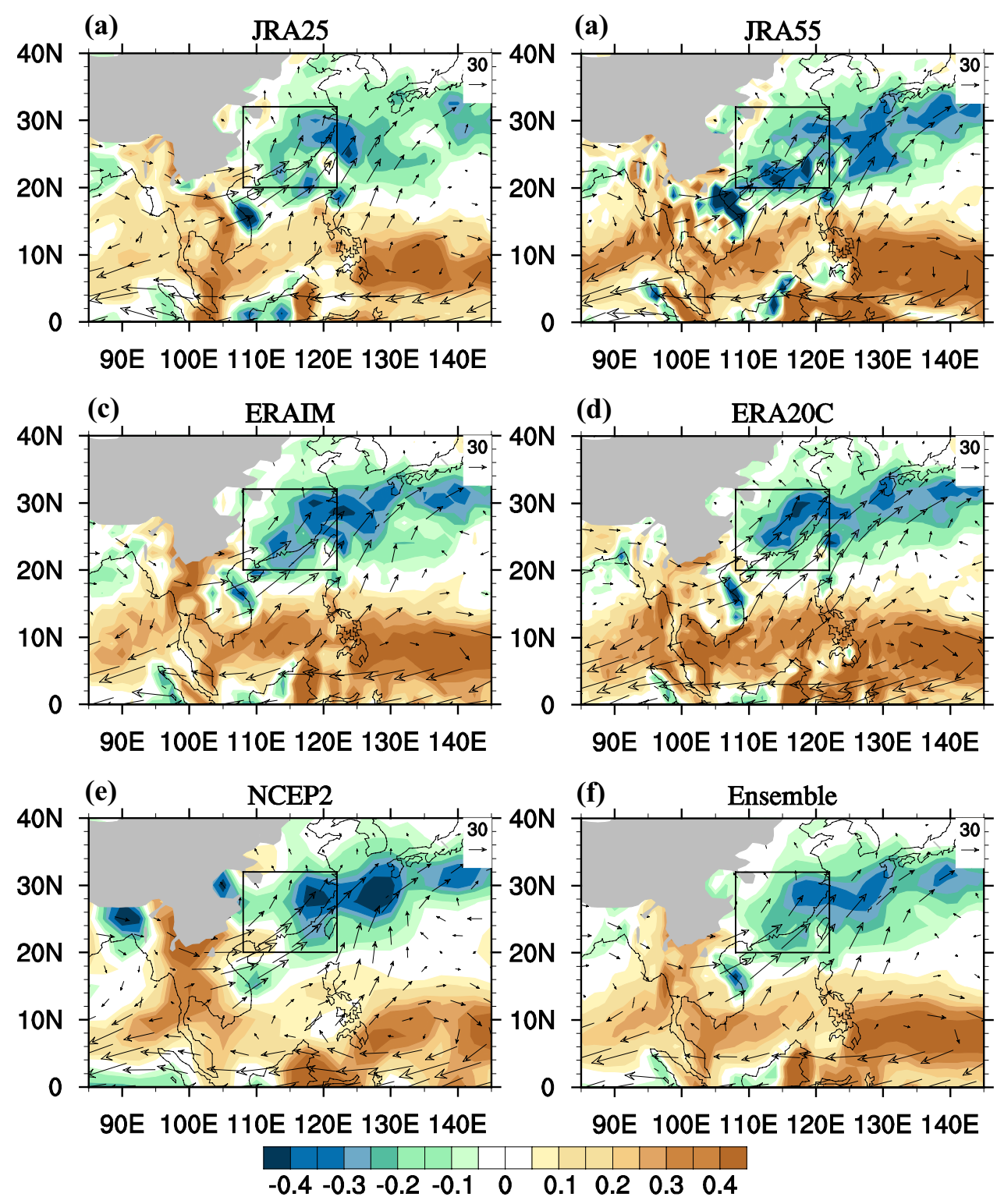

tion. JRA55 has a rainfall intensity $\left(5.22 \mathrm{~mm} \mathrm{day}^{-1}\right)$ closest to observation $\left(5.25 \mathrm{~mm} \mathrm{day}^{-1}\right)$ among the five reanalysis datasets [4.94 (4.54-5.32) $\left.\mathrm{mm} \mathrm{day}^{-1}\right]$. All five reanalysis datasets exhibit a strong westerly wind flow over the southern Tibetan Plateau and southwest wind flow over the western North Pacific that are the two main channels remotely supplying water vapor for the SPR. Locally, the moisture budget diagnosis shows that the SPR is primarily contributed by evaporation [2.98 (2.69-3.67) $\mathrm{mm} \mathrm{day}^{-1}$ ] and vertical moisture advection $\left[2.54(1.83-2.79) \mathrm{mm}\right.$ day $\left.^{-1}\right]$. Area-averaged horizontal moisture advection and residual component contribute little to the total SPR precipitation. NCEP2 overestimates evaporation $\left(3.67 \mathrm{~mm} \mathrm{day}^{-1}\right)$ and ERA20C underestimates vertical moisture advec- tion $\left(1.83 \mathrm{~mm} \mathrm{day}^{-1}\right)$ compared with other reanalysis datasets.

2. The long-term trend (see Fig. 10b for a summary of major results): The time series of SPR in all five reanalysis datasets are highly consistent with observation. The precipitation trend in both observation $\left[-0.38 \mathrm{~mm} \mathrm{day}^{-1}(10 \text { year })^{-1}\right]$ and reanalysis datasets $\left\{-0.51[-0.26\right.$ to -0.79$\left.] \mathrm{mm} \mathrm{day}^{-1}(10 \text { year })^{-1}\right\}$ shows a significantly negative trend from 1980 to 2012 , and the trend in ERAIM [ $\left.-0.41 \mathrm{~mm} \mathrm{day}^{-1}(10 \text { year })^{-1}\right]$ is closest to observation. The moisture budget diagnosis shows that the SPR precipitation anomalies are dominated by changes in vertical moisture advection, with the dynamic term contribution being far larger than 

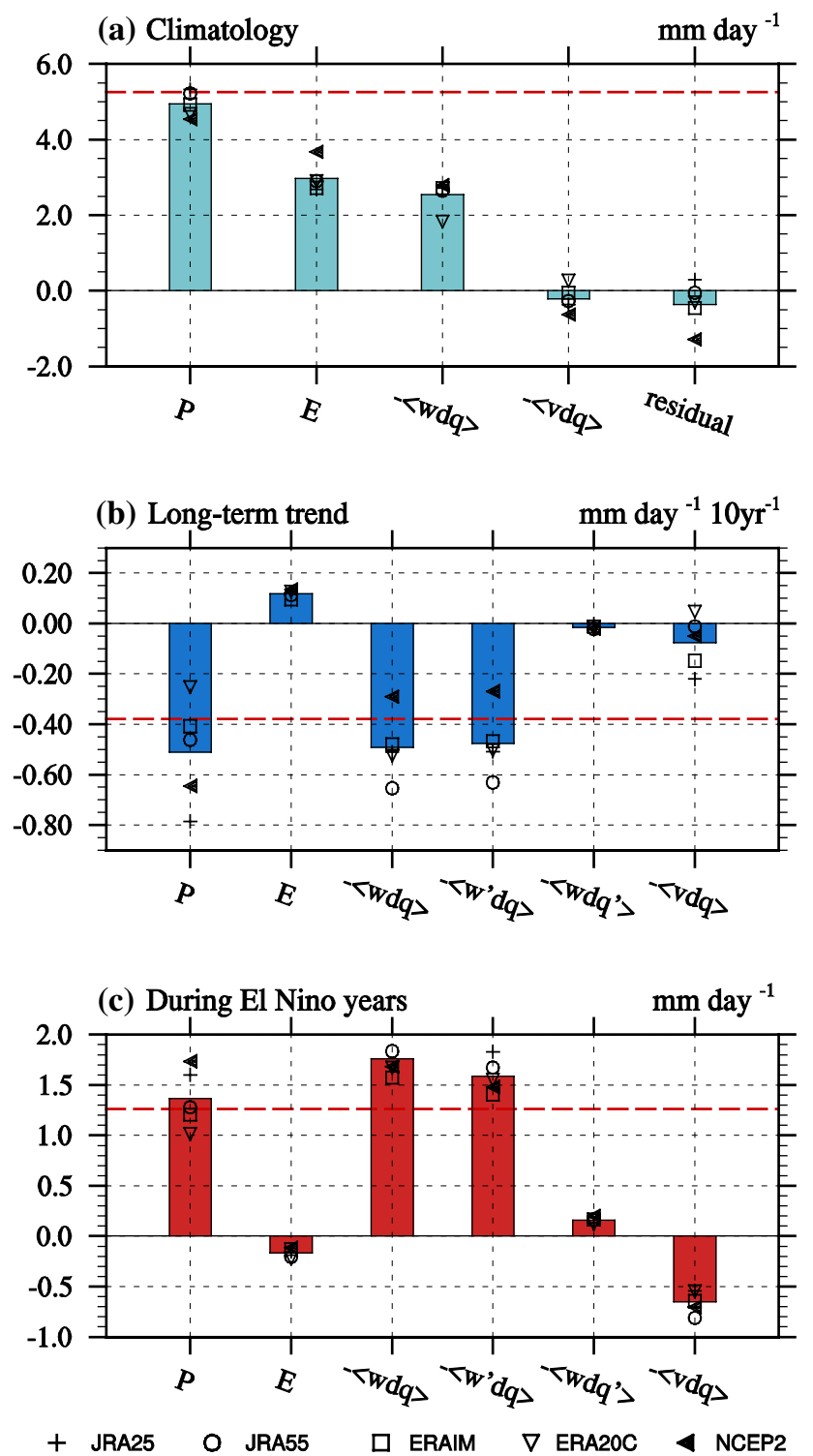

Fig. 10 Moisture budget components from 1980 to 2012 over the major rainfall center for the five reanalysis datasets: a Moisture budget components for climatology, the bars indicate precipitation, evaporation, vertical moisture advection, horizontal moisture advection and the residual term in the ensemble mean of five reanalysis datasets (unit: $\mathrm{mm} \mathrm{day}^{-1}$ ), different symbols represent results of each reanalysis dataset, the red dash line indicates climatological SPR precipitation in GPCP. b The same as a, but the bars indicate the longterm trend of precipitation, evaporation, vertical moisture advection, the dynamic term, the thermodynamic term and the horizontal moisture advection term [unit: $\mathrm{mm} \mathrm{day}^{-1}(10 \text { year })^{-1}$ ], the red dash line indicates the long-term trend of the SPR in GPCP. $\mathbf{c}$ The same as b, but for composite results in the El Niño decaying springs

the thermodynamic term. The weakening of ascending motion leads to the decreasing trend of SPR.

3. Interannual variability (see Fig. 10c for a summary of major results): The spatial distributions of precipitation anomalies in El Niño are consistent with the standard deviation (PCC could be up to 0.87). All five reanalysis datasets can capture anomalous WNPAC, and then reproduce the positive precipitation anomalies over southeastern China, with PCCs of 0.64 [0.19-0.70]. ERAIM is superior (PCC is 0.70) in capturing the spatial distribution of precipitation anomalies. NCEP2 shows relatively lower skill (PCC is 0.19). The moisture budget diagnosis shows that the enhancement of upward motion related to the WNPAC dominates the positive precipitation anomalies.

\section{Discussion}

How to understand the difference of precipitations derived from five reanalysis data? The five reanalysis datasets differ in atmospheric forecast model, model resolution, convective parameterization schemes, data assimilation algorithm and satellite data processing (Table 1), which could cause different results derived from different reanalysis (Bosilovich et al. 2008; Lin et al. 2014). For example, the data assimilation methodology of ERAIM and JRA55 is fourdimensional variational analysis (4D-Var), which is the state-of-the-art data assimilation method. What's more, the model resolution of ERAIM (T255L60) and JRA55 (TL319L60) are relatively higher than other three reanalysis datasets (T106L40 for JRA25, T159L91 for ERA20C and T62L28 for NCEP2). In our results, both ERAIM and JRA55 have relatively higher skill in reproducing the climatology and interannual variability of the SPR, indicating that the model resolution and data assimilation algorithm could influence the performance of reanalysis. In addition, the ERAIM and JRA55 also assimilate the radiance products in satellite data. The ERA20C uses the same data assimilation method as ERAIM and uses a relatively higher vertical resolution, but it just assimilated observational surface pressures, mean sea level pressures and surface marine winds. That's the reason why the performance of ERAIM is better than ERA20C in reproducing the climatology and interannual variability of the SPR.

What are the mechanisms for the decreasing trend of the SPR? Although this is beyond the scope of this study, we note that several mechanisms have been suggested. The dynamics of spring rainfall reduction in recent decades over southeastern China is associated with anomalous atmospheric circulation induced by the La Niña-like pattern with warming in the tropical Indian Ocean and western Pacific region (Qiu et al. 2009; Zhu et al. 2014). In addition, the reduction of late spring precipitation concurs with the upper-level cooling, which is associated with an anomalous meridional cell over southeastern China and is found to strongly link to the North Atlantic Oscillation (Xin et al. 2006, 2008). The aerosol forcing 
is also a potential mechanism. The anthropogenic aerosols could make a shortened duration and reduced rainfall amount to the SPR (Deng et al. 2014). Modeling study of the effect of anthropogenic aerosols shows that the forcing of anthropogenic aerosols could induce the descending motion over southern China and lead the decreasing trend of the SPR (Kim et al. 2007; Hu and Liu 2013). Although the mechanisms dominating the weakening trend of SPR deserves further study, the current analysis presents an observational metric for examining the suggested mechanisms and may serve as a basis for model simulation of spring drought over southeastern China.

Why do only the positive or warm events of ENSO have significant influences on spring rainfall? There exists an asymmetry of the western North Pacific (WNP) low-level atmospheric circulation anomalies between the El Niño and La Niña during the cold seasons from winter to spring. Due to the longitudinal shifting of anomalous heating associated with El Niño and La Niña and the amplitude asymmetry of the associated sea surface temperature anomalies (SSTAs) in the WNP, the anomalous WNP cyclone center during La Niña shifts westward relative to an anomalous WNP anticyclone (WNPAC) center during El Niño (Wu et al. 2010). Following the asymmetric response of WNP low level atmospheric circulations, the enhanced precipitation over the southeastern China during El Niño years are more significant (Feng and $\mathrm{Li}$ 2011; Guo et al. 2017). Hence in our study, we focus on the influence of El Niño on the SPR.

Finally, there is an increasing trend of available reanalysis datasets. How to reliably use these reanalysis data sets has been of great concern to the climate research community. Based on our evaluation, among the five sets of reanalysis data we evaluated, both the JRA55 and ERAIM show higher skills in reproducing the climatology and changes of the SPR in comparison to the observations, and are thus recommenced for climate variability and climate change researches with focus on East Asia.

Acknowledgements This work was jointly supported by National Natural Science Foundation of China under Grant Nos. 41330423, 41420104006, and R\&D Special Fund for Public Welfare Industry (meteorology) (GYHY201506012).

Open Access This article is distributed under the terms of the Creative Commons Attribution 4.0 International License (http:// creativecommons.org/licenses/by/4.0/), which permits unrestricted use, distribution, and reproduction in any medium, provided you give appropriate credit to the original author(s) and the source, provide a link to the Creative Commons license, and indicate if changes were made.

\section{References}

Adler RF, Huffman GJ, Chang A, Ferraro R, Xie PP, Janowiak J, Rudolf B, Schneider U, Curtis S, Bolvin D, Gruber A, Susskind J, Arkin P, Nelkin E (2003) The version-2 global precipitation climatology project (GPCP) monthly precipitation analysis (1979-present). J Hydrometeorol 4(6):1147-1167. doi:10.1175/1525-7541(2003)004<1147:tvgpcp >2.0.co;2

Bosilovich MG, Chen J, Robertson FR, Adler RF (2008) Evaluation of global precipitation in reanalyses. J Appl Meteorol Climatol 47(9):2279-2299. doi:10.1175/2008JAMC1921.1

Chen J, Wen Z, Wu R, Chen Z, Zhao P (2014) Interdecadal changes in the relationship between Southern China winter-spring precipitation and ENSO. Clim Dyn 43(5-6):1327-1338. doi:10.1007/ s00382-013-1947-x

Chou C, Lan CW (2012) Changes in the annual range of precipitation under global warming. J Clim 25(1):222-235. doi:10.1175/ JCLI-D-11-00097.1

Chou C, Neelin JD, Chen CA, Tu JY (2009) Evaluating the "richget-richer" mechanism in tropical precipitation change under global warming. J Clim 22(8):1982-2005. doi:10.1175/2008J CLI2471.1

Chou C, Chiang JCH, Lan CW, Chung CH, Liao YC, Lee CJ (2013) Increase in the range between wet and dry season precipitation. Nat Geosci 6(4):263-267. doi:10.1038/ngeo1744

Dee DP et al (2011) The ERA-Interim reanalysis: configuration and performance of the data assimilation system. Q J R Meteor Soc 137:553-597. doi:10.1002/qj.828

Deng J, Xu H, Ma H, Jiang Z (2014) Numerical study of the effect of anthropogenic aerosols on spring persistent rain over eastern China. J Meteorol Res 28:341-353. doi:10.1007/ s13351-014-3198-0

Ebita A et al (2011) The Japanese 55-year reanalysis "JRA-55": an interim report. SOLA 7:149-152. doi:10.2151/sola.2011-038

Feng J, Li J (2011) Influence of El Niño Modoki on spring rainfall over south China. J Geophys Res 116:D13102. doi:10.1029/20 10JD015160

Feng L, Zhou T (2012) Water vapor transport for summer precipitation over the Tibetan Plateau: multi-dataset analysis. J Geophys Res 117:D20114. doi:10.1029/2011JD017012

Feng L, Li T, Yu W (2014) Cause of severe droughts in Southwest China during 1951-2010. Clim Dyn 43:2033-2042. doi:10.1007/ s00382-013-2026-Z

Guo Z, Zhou T, Wu B (2017) The asymmetric effects of El Niño and La Niña on the East Asian winter monsoon and their simulation by CMIP5 atmospheric models. J Meteorol Res 31(1):1-14. doi:10.1007/s13351-017-6095-5

Held IM, Soden BJ (2006) Robust responses of the hydrological cycle to global warming. J Clim 19(21):5686-5699

Hu N, Liu X (2013) Modeling study of the effect of anthropogenic aerosols on late spring drought in South China. Acta Meteorol Sin 27(5):701-715. doi:10.1007/s13351-013-0506-z

Huang P, Xie SP, Hu K, Huang G, Huang R (2013) Patterns of the seasonal response of tropical rainfall to global warming. Nat Geosci 6(5):357-361. doi:10.1038/ngeo1792

Huang B, Banzon VF, Freeman E, Lawrimore J, Liu W, Peterson TC, Smith TM, Thorne PW, Woodruff SD, Zhang HM (2015a) Extended reconstructed sea surface temperature version 4 (ERSST. v4). Part I: upgrades and intercomparisons. J Clim 28(3):911-930. doi:10.1175/JCLI-D-14-00006.1

Huang DQ, Zhu J, Zhang YC, Wang J, Kuang XY (2015b) The impact of the East Asian subtropical jet and polar front jet on the frequency of spring persistent rainfall over Southern China in 1997-2011. J Clim 28(15):6054-6066. doi:10.1175/ JCLI-D-14-00641.1 
Huffman GJ et al (1997) The global precipitation climatology project (GPCP) combined precipitation dataset. Bull Am Meteor Soc 78:5-20. doi:10.1175/1520-0477(1997)078<0005:TGPCPG $>2$. $0 . \mathrm{CO} ; 2$

Jones PW (1999) First-and second-order conservative remapping schemes for grids in spherical coordinates. Mon Weather Rev 127(9):2204-2210

Kanamitsu M, Ebisuzaki W, Woollen J, Yang SK, Hnilo JJ, Fiorino M, Potter GL (2002) NCEP-DOE AMIP-II reanalysis (R-2). Bull Am Meteor Soc 83:1631-1643. doi:10.1175/BAMS-83-11-1631

Kim MK, Lau WKM, Kim KM, Lee WS (2007) A GCM study of effects of radiative forcing of sulfate aerosol on large scale circulation and rainfall in East Asia during boreal spring. Geophys Res Lett. doi:10.1029/2007GL031683

Li H, Lin Z, Song Y, Xu J (2013) Analysis of the possible factors that influence March precipitation anomalies over South China. Chin J Atmos Sci 37(3):719-730 (In Chinese)

Li Z, Yang S, He B, Hu C (2016) Intensified springtime deep convection over the South China Sea and the Philippine sea dries Southern China. Sci Rep 6:30470. doi:10.1038/srep30470

Lin R, Zhou T, Qian Y (2014) Evaluation of global monsoon precipitation changes based on five reanalysis datasets. J Clim 27(3):1271-1289. doi:10.1175/JCLI-D-13-00215.1

Ma S, Zhou T (2015) Precipitation changes in wet and dry seasons over the 20th century simulated by two versions of the FGOALS model. Adv Atmos Sci 32(6):839-854. doi:10.1007/ s00376-014-4136-x

Ma S, Zhou T (2016) Robust strengthening and westward shift of the Tropical Pacific Walker circulation during 1979-2012: a comparison of 7 sets of reanalysis data and 26 CMIP5 models. J Clim 29(9):3097-3118. doi:10.1175/JCLI-D-15-0398.1

Onogi K et al (2007) The JRA-25 reanalysis. J Meteor Soc Jpn 85:369-432. doi:10.2151/jmsj.85.369

Pan W, Jiang C (2014) The march and intraseasonal oscillation of the spring persistent rains over South China. J Trop Meteorol 30(1):83-91 (In Chinese)

Qiang X, Yang X (2013) Relationship between the first rainy season precipitation anomaly in South China and the sea surface temperature anomaly in the Pacific. Chin J Geophys 56(8):25832593 (In Chinese)

Qiu Y, Cai W, Guo X, Pan A (2009) Dynamics of late spring rainfall reduction in recent decades over southeastern China. J Clim 22(8):2240-2247. doi:10.1175/2008JCLI2809.1

Seager R, Naik N, Vecchi GA (2010) Thermodynamic and dynamic mechanisms for large-scale changes in the hydrological cycle in response to global warming. J Clim 23(17):4651-4668. doi:10.1 175/2010JCLI3655.1

Stickler A, Brönnimann S, Valente MA, Bethke J, Sterin A, Jourdain S, Roucaute E, Vasquez MV, Reyes DA, Allan R, Dee D (2014) ERA-CLIM historical surface and upper-air data for future reanalyses. Bull Am Meteor Soc 95:1419-1430. doi:10.1175/ BAMS-D-13-00147.1

Sun C, Yang S (2012) Persistent severe drought in southern China during winter-spring 2011: large-scale circulation patterns and possible impacting factors. J Geophys Res 117:D10112. doi:10. 1029/2012JD017500

Tian SF, Yasunari T (1998) Climatological aspects and mechanism of spring persistent rains over central China. J Meteor Soc Jpn 76:57-71

Trenberth KE (1997) The definition of el nino. Bull Am Meteor Soc 78(12):2771
Trenberth KE, Guillemot CJ (1995) Evaluation of the global atmospheric moisture budget as seen from analyses. J Clim 8(9):22552272. doi:10.1175/1520-0442(1995)008<2255:EOTGAM > 2.0 .CO;2

Wan RJ, Wu GX (2007) Mechanism of the spring persistent rains over southeastern China. Sci China Ser D Earth Sci 50(1): 130-144. doi:10.1007/s11430-007-2069-2

Wan RJ, Wu GX (2008) Temporal and spatial distribution of spring persistent rains over southeast China. Acta Meteorol Sin 66(3):310-319 (In Chinese)

Wan RJ, Zhao BK, Hou YL (2008) The interannual variability of spring persistent rains over southeast China and influencing factors. Plat Meteorol 27(B12):118-123 (In Chinese)

Wan RJ, Zhao BK, Wu GX (2009) New evidences on the climatic causes of the formation of the spring persistent rains over southeastern China. Adv Atmos Sci 26(6):1081. doi:10.1007/ s00376-009-7202-z

Wang B, Zhang Q (2002) Pacific-East Asian teleconnection. Part II: how the Philippine Sea anomalous anticyclone is established during El Niño development. J Clim 15(22):3252-3265. doi:10.1175/1520-0442(2002)015<3252:PEATPI >2.0.CO;2

Wang B, Wu R, Fu X (2000) Pacific-East Asian teleconnection: how does ENSO affect East Asian climate? J Clim 13(9):1517-1536. doi:10.1175/1520-0442(2000)013<1517:PEATHD > 2.0.CO;2

Wang H, Xue F, Zhou G. (2002) The spring monsoon in south china and its relationship to large-scale circulation features. Adv Atmos Sci 19(4):651-664. doi:10.1007/s00376-002-0005-0

Wen Z, Wu N, Feng Y, Lin L, Yuan Z, Chen B (2007) A quantitative diagnosis for the mechanisms of spring droughts in south China. Chin J Atmos Sci 31(6):1223-1236 (In Chinese)

Wu B, Li T, Zhou T (2010) Asymmetry of atmospheric circulation anomalies over the western North Pacific between El Niño and La Niña. J Clim 23(18):4807-4822. doi:10.1175/2010J CLI3222.1

Wu H, Yang S, Jiang X (2015) Anomalous onset date of the first rainy season in South China and its relationship with the variation of the atmospheric circulation and SST. Acta Meteorol Sin 73(2):319-330 (In Chinese)

Xin X, Yu R, Zhou T, Wang B (2006) Drought in late spring of South China in recent decades. J Clim 19(13):3197-3206. doi:10.1175/ JCLI3794.1

Xin X, Li Z, Yu R, Zhou T (2008) Impacts of upper tropospheric cooling upon the late spring drought in East Asia simulated by a regional climate model. Adv Atmos Sci 25(4):555-562. doi:10.1007/s00376-008-0555-x

Yang F, Lau KM (2004) Trend and variability of China precipitation in spring and summer: linkage to sea-surface temperatures. Int J Clim 24(13):1625-1644. doi:10.1002/joc.1094

Zhang J, Li L, Zhou T, Xin X (2013) Evaluation of spring persistent rainfall over East Asia in CMIP3/CMIP5 AGCM simulations. Adv Atmos Sci 30(6):1587-1600. doi:10.1007/ s00376-013-2139-7

Zhou TJ, Yu RC (2005) Atmospheric water vapor transport associated with typical anomalous summer rainfall patterns in China. J Geophys Res 110:D08104. doi:10.1029/2004JD005413

Zhu Z, Li T, He J (2014) Out-of-phase relationship between boreal spring and summer decadal rainfall changes in southern China. J Clim 27(3):1083-1099. doi:10.1175/JCLI-D-13-00180.1 